Research Article

\title{
Hydro-treating and Hydro-isomerisation of Sunflower Oil using Pt/SAPO-11: Influence of Templates in Ultrasonic Assisted with Hydrothermal Synthesis
}

\author{
Shanmugam Palanisamy ${ }^{1, *)}$, Durona Palanisamy ${ }^{1}$, Mugaishudeen Gul ${ }^{1}$, Kannan Kandasamy ${ }^{1}$, \\ Borje Sten Gevert ${ }^{2}$
}

${ }^{1}$ Kongu Engineering College, Erode-638 060, India.

${ }^{2}$ Kempross AB, Larseredslyckor 14, 42539 Hisingskärra, Sweden.

Received: 27th December 2020; Revised: 15 th March 2021; Accepted: $16^{\text {th }}$ March 2021

Available online: $16^{\text {th }}$ March 2021; Published regularly: March 2021

\section{Abstract}

Pt/SAPO-11 mesopores type materials has successfully synthesized using different templates, such as: diethylamine (DEA), dimethylamine (DMA), and n-propylamine (n-PA), under ultrasonication coupled with hydrothermal treatment or independently with hydrothermal treatment. The influences of structure directing agent (SDA) and synthesis method are investigated by different characterization techniques and the role of the material as catalyst in hydrotreating of sunflower oil has examined. The synthesized materials have been characterized by X-ray Diffraction (XRD), Scanning Electron Microscope (SEM), and Fourier Transform Infra Red (FT-IR) techniques. It is found that SAPO-11 material which has synthesized with n-PA as a template has the characteristics of high silicon incorporation. Hydrotreating of sunflower oil is carried out in a fixed bed reactor with Pt impregnated SAPO11 catalyst and a detailed study on the isomerization is performed by varying the operating parameters like temperature and space velocity. The high selectivity of Pt/SAPO-11 catalyst is achieved by uniform pore size and acidity. Also the pore opening of the catalyst has a major effect in the selectivity of the catalyst. Further, it represents a higher ratio of isomers compared to other synthesized catalysts on hydro-treating of sunflower oil.

Copyright ( $\odot 2021$ by Authors, Published by BCREC Group. This is an open access article under the CC BY-SA License (https://creativecommons.org/licenses/by-sa/4.0).

Keywords: SAPO-11; Zeolite; Mesoporous; Hydrothermal; Ultrasonication; Hydrotreating; Hydroisomerisation; Hydrodeoxygenation

How to Cite: S. Palanisamy, D. Palanisamy, M. Gul, K. Kandasamy, B.S. Gevert (2021). Hydro-treating and Hydro-isomerisation of Sunflower Oil using Pt/SAPO-11: Influence of Templates in Ultrasonic Assisted with Hydrothermal Synthesis. Bulletin of Chemical Reaction Engineering \& Catalysis, 16(1), 120-135 (doi:10.9767/bcrec.16.1.9889.120-135)

Permalink/DOI: https://doi.org/10.9767/bcrec.16.1.9889.120-135

\section{Introduction}

The growing demand of fuel is observed and use of renewable feedstock in replacing the conventional fuel in transportation can be the alter solution for the fossil fuel dependency. One such renewable source can be the direct blend of vegetable oil and gas oil in diesel engine [1-5]. But

* Corresponding Author.

Email: shapal.chem@kongu.edu (S. Palanisamy);

Tel.: +918098079696 the study proved that the presence of carboxylic group in vegetable oil has increase the $\mathrm{NO}_{\mathrm{x}}$ emission and corrosiveness in the fuel tank. So, in order to reduce this default, refineries have been upgrading this blend in the hydroprocessing technology by hydrodeoxygenation (HDO) mechanism to remove carboxylic group [1-7]. In other way, direct HDO of tall or vegetable oil may convert into higher straight chain hydrocarbon composition through fatty acids as intermediates. The straight chain hydrocarbon 
from vegetable oil can produce the composition of larger-chain hydrocarbon (n-heptadecane and n-octadecane) [3-7]. This paraffinic gas oil or diesel-like fuel composition may have a problem by increasing the cloud point of the middle distillates. The diesel-like fuel having high content of paraffinic hydrocarbon from different sources is difficult to use under cold weather conditions. To deal the cold properties of upgraded gas oil, it is necessary to reduce the freezing point of higher straight-chain hydrocarbons by increasing the branched carbon compounds in the long chain which can be attained through isomerization mechanism [6-8]. So, the isomeric compounds can reduce the cloud point, however, the properties of cold flow plugging point can minimize by increasing the number of methyl or ethyl branch in the hydrocarbon. Figure 1 shows the change in the melting point of isomeric compounds with methyl branch in hydrocarbon chain, respectively.

In 1962, zeolites were introduced by the Mobil Oil Company to be used as a cracking catalyst in oil refinery technology. It has several industrial applications that provide many advantages to the refinery industry, including ion exchange, shape selectivity, selective absorbent, high activity and selectivity in a wide range of products and high thermal stability. However, the cations of several zeolites reside inside the pore channel for the capability in branching hydrocarbons. The shape selectivity of zeolites is the ability to selectively catalyze reagents or reactants. This ability is achieved through their pore structure and the thermal stability, at which this can be thermally stable up to $600{ }^{\circ} \mathrm{C}$. Several studies have reported minor destruction of the structure caused by

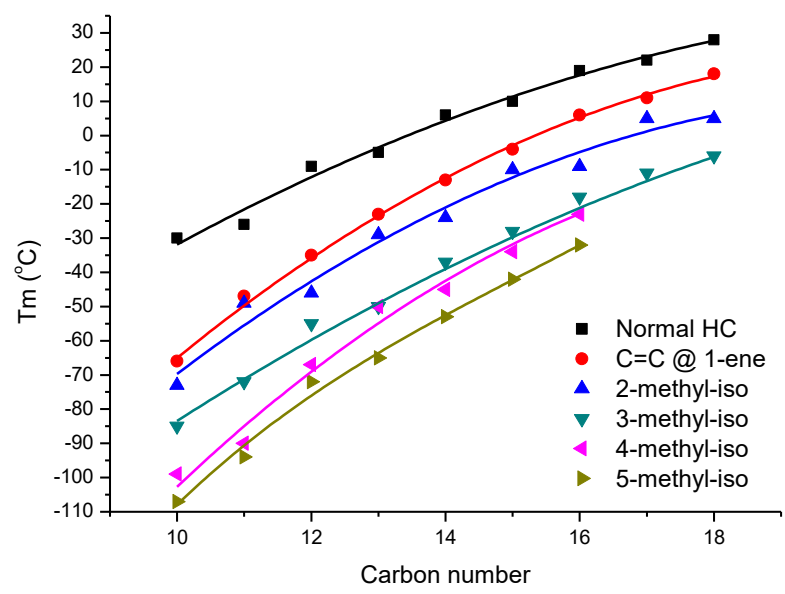

Figure 1. Melting point for different hydrocarbons with position of isomeric compounds. [Source: www.nist.gov] dealumination, which modify the pore volume $[9,10]$. Except the alumination on material due to calcined temperature, this may not affect pore volume drastically. The thermal stability of zeolites increases when the $\mathrm{SiO}_{2} / \mathrm{Al}_{2} \mathrm{O}_{3}$ ratio increases and the decomposition of zeolites occur near a temperature of about $700{ }^{\circ} \mathrm{C}$. The acidic property of zeolites vary by changing the $\mathrm{SiO}_{2} / \mathrm{Al}_{2} \mathrm{O}_{3}$ ratio [11-14]. In zeolites, acid sites are classified according to the classical Bronsted and Lewis models of acidity [11-17]. A high $\mathrm{SiO}_{2} / \mathrm{Al}_{2} \mathrm{O}_{3}$ ratio is stable in concentrated mineral acid, whereas a low $\mathrm{SiO}_{2} / \mathrm{Al}_{2} \mathrm{O}_{3}$ ratio is rather fragile in the presence of acid. In contrast, the high $\mathrm{SiO}_{2} / \mathrm{Al}_{2} \mathrm{O}_{3}$ ratio is unstable in the basic solution but the low $\mathrm{SiO}_{2} / \mathrm{Al}_{2} \mathrm{O}_{3}$ ratio can enable increase in stability. Consequently, the acidic property of zeolites is mainly dependent on the $\mathrm{SiO}_{2} / \mathrm{Al}_{2} \mathrm{O}_{3}$ ratio as well as the operating temperature in the reactor.

Zeolites are crystalline aluminosilicates molecular sieve containing uniform pores and acidic sites, which is widely used in water treatment, fine chemical synthesis, upgrading fuels, gas separation, emission control and adsorbent. Zeolites are synthesized and its properties have been mainly studied with different sources, methods and application by various researches [9-17]. From this series, in the last few decades, synthesis of phosphate incorporated silica-aluminates materials are popularized because of their material as better catalyst performance and stability in hydroprocessing of bio-based fuel synthesis from fat-rich material. Silicoaluminophosphate (SAPO) zeolite is used as a catalyst support in various processes such as upgrading of fuel, chain growth of lighter hydrocarbon, hydrocracking of long chain hydrocarbon and conversion of vegetable oil into bio-diesel. This material has been used for isomerisation, aromatization, hydrogenation, alkylation and dehydrogenation processes in refinery processes. The isomerisation is the branching of hydrocarbons where transformation of molecules which has same number of atoms takes place irrespective of their atomic arrangement on both hydrogenation and dehydrogenation in duel mechanism. Both mechanism such as branching of hydrocarbon and hydrogenolysis of the fatty acids into paraffinic or olefinic hydrocarbons are widely investigated using SAPO as a support material in solid catalyst.

Solid acid catalysts (such as zeolites loaded with transition metal $(\mathrm{Pt})$ ) on activation are used in the industrial isomerization process. The catalysts are often called bi-functional as they contain both acid and metal functions. 
Here, the functional activity of catalyst can act as acidic solid material and hydrogenationdehydrogenation process [2,11-12]. Generally, zeolites with alkaline metal cations are colorless powders. It has a crystalline porous aluminium silicate intra-bonds with a vast three dimension network structure of tetrahedral coordinated $\mathrm{SiO}_{4}$ and $\mathrm{Al}_{2} \mathrm{O}_{3}$, producing a lowdensity micro-porous structure. Color presenting on catalysts may occur because they contain transition metals or modifying zeolites by an ion exchange method. Most zeolites can be dehydrated without the collapse of the framework by calcination on temperatures between 350 and $500{ }^{\circ} \mathrm{C}$ [12-16].

The research study aimed to hydrotreating the fatty acids in the presences of Pt metal impregnated over the surface of alumina-SAPO11 support material. The synthesized SAPO-11 is used as a base support for the catalyst for the conversion of vegetable oil into diesel-like hydrocarbon. Though, the diesel-like hydrocarbon is produced in long straight-chain hydrocarbon such as heptadecane (C17) or octadecane (C18), this hydrocarbon can involve the cold plugging problem in fuel injection pipe due to solidification at room temperature. To reduce the plugging problem, it is important to branch the long straight-chain hydrocarbon. So, the importance of synthesis of Pt/SAPO-11 has focused to involve in both hydrotreatment and branching of the fatty acids within the moderate temperature range $\left(290\right.$ to $\left.380{ }^{\circ} \mathrm{C}\right)$. Here, the study involves hydrogenation and dehydrogenation over the sunflower oil as reference vegetable oil (refined form of triglyceride) at different operating parameters of temperature and pressure. The synthesis of material can carried out by different templates, such as: diethylamine (DEA), dimethylamine (DMA), and n-propylamine (n-PA), using $\mathrm{SiO}_{2}$ and $\mathrm{Al}_{2} \mathrm{O}_{3}$ under ultrasonication coupled with hydrothermal treatment or independently with hydrothermal treatment. The main purpose of the investigation is to analyze the activity and performance of the synthesis of Pt/SAPO-11 using various templates in supported zeolite catalyst for the dual purpose on both hydrotreating of vegetable oil and upgrading into diesel-grade fuel within the optimized condition.

\section{Methods and Materials}

\subsection{Materials}

The raw materials used for producing Pt/SAPO-11 and support metal oxide contain colloidal silica (40 wt\% suspension in water from Sigma-Aldrich), aluminium hydroxide
(Universal Chemicals, India), orthophosphoric acid (85\% Merck), Tetra amine platinum(II) chloride hydrate $(99.99 \%$ Sigma-Aldrich) dimethylamine (80\% Loba chemie), dimethylamine (99\% Nice Chemicals) and n-propylamine (99\% Merck).

\subsection{Catalyst Preparation}

Initially, $10.33 \mathrm{~g}$ of aluminium oxide $\left(\mathrm{Al}_{2} \mathrm{O}_{3}\right)$ which acts as the alumina source is added to $16.5 \mathrm{~mL}$ of distilled water (deionized) and stirred by magnetic stirrer for 50 minutes at room temperature. The gel formation is achieved better in $\mathrm{Al}_{2} \mathrm{O}_{3}$ than compared to other alumina sources like aluminium chloride $\left(\mathrm{AlCl}_{3}\right)$. While stirring, $3 \mathrm{~mL}$ of orthophosphoric acid $\left(\mathrm{H}_{3} \mathrm{PO}_{4}\right)$ is added in drop wise to the alumina water mixture for 30 minutes. After addition of $\mathrm{H}_{3} \mathrm{PO}_{4}$ to the mixture, $0.764 \mathrm{~g}$ of silica sol is added. Further, $20 \mathrm{~mL}$ of ditheylamine (DEA) (S5, S6) is added to the mixture which acts as a structure directing agent (template) and the stirring is allowed to continue for 3 hours. By substituting various templates such as dimethylamine (DMA) (S3, S4) and n-propylamine (n-PA) (S1, S2) SAPO-11 has prepared. The obtained solution is stirred until a gel is formed and it is transferred into an ultrasonic bath in a shielded container at $120{ }^{\circ} \mathrm{C}$ for 6 hours maintained at 60 (reported as an ultrasonic - S2, S4, and S6). The ultrasonic method has carried on $39 \mathrm{kHz}$ and $60 \mathrm{~W}$ conditions.

The same preparation technique has followed to prepare the gel solution and after sonication the samples are subjected to be kept in a hydrothermal reactor at a temperature of 180 ${ }^{\circ} \mathrm{C}$ for 24 hours (reported as an ultrasonic and hydrothermal process - S1, S3 and S5).The same procedure is repeated for the samples of different templates. The samples are dried at $110{ }^{\circ} \mathrm{C}$ for 24 hours and calcined at a high temperature of $600{ }^{\circ} \mathrm{C}$ for 52 hours. (The sample was calcined for $52 \mathrm{~h}$ in order to burn out the template present over the surface)

Prepared SAPO-11 and $\gamma-\mathrm{A}_{2} \mathrm{O}_{3}$ (Disperal and Locron) is blended in a ratio of 40:60 wt\%, and the hydrated blend has extruded in 1/32" material size. The support material was dried at $110^{\circ} \mathrm{C}$ for 5 hours and calcined at $350{ }^{\circ} \mathrm{C}$ for 6 hours. After drying and calcination, platinum was loaded using $\mathrm{Pt}\left(\mathrm{NH}_{3}\right)_{4} \mathrm{Cl}_{2}$ solutions by impregnation to get the content of $0.5 \mathrm{wt} \% \mathrm{Pt}$. The catalysts are dried at $110{ }^{\circ} \mathrm{C}$ for 12 hours and calcined at the temperature of $400{ }^{\circ} \mathrm{C}$ for 4 hours in air. Finally, $\mathrm{H}_{2}$ in-situ activation is performed at $400{ }^{\circ} \mathrm{C}$ for 4 hours. 


\subsection{Experimental Set-up}

The experimental set-up consists of a feed tank, fixed-bed reactor, product tank, gas collector and dossier pump [18,19]. The fixed-bed reactor is fixed with an electric furnace and connected with an instrumental controller to regulate temperature and pressure conditions. The catalyst is placed at $62.6 \mathrm{~mm}(31 \mathrm{~mL})$ in height from $619.4 \mathrm{~mm}$ as total vertical height of the reactor. The distance of the catalyst from the top or bottom line is $278.4 \mathrm{~mm}$ while the remaining part of reactor space can consists of borosilicate glass pellets. The outlet goes to a separator and the reactor pressure is controlled on the gas exit of the separator with manual collection in liquid and gas samples. The gas outlet and liquid products are analyzed with gas chromatography as represented in below section. Hydrogen was supplied at volumetric rate of $1200 \mathrm{~mL} / \mathrm{h}$ in $3: 1$ hydrogen to hydrocarbon ratio.

\subsection{Analysis Method}

The liquid sample analysis is performed using a gas chromatograph (GC) technique (Varian 3400) equipped with a packed column (Elite-5MS column, $30 \mathrm{~m}$ x $0.3 \mathrm{~mm}$. I.D., $1.0 \mathrm{~m}$ film thickness and dimethyl polysiloxane) and flame ionization detector (FID). The Varian 4270 is the integrator to data computation. Samples $(5 \mu \mathrm{L})$ were injected into an injector through a micro-syringe. The outlet gas sample from the reactor has analyzed using the Clarus 500 GC online. This GC was connected with 600 link switch controllers, with the signal that has integrated to receive data. The gas analysis has an inlet and outlet sampling value for FID and TCD detectors and has four valves actuated by Nitrogen gas at 0.40 MPa. Gas analyses have consisted of a thermal conductivity detector (TCD) for analyzing $\mathrm{CO}, \mathrm{CO}_{2}, \mathrm{CH}_{4}$ and $\mathrm{H}_{2}$, as well as the FID for analyzing hydrocarbons. Helium was used as carrier gas for the TCD, which was maintained at $200{ }^{\circ} \mathrm{C}$ with oven heat-up of 40 to $60{ }^{\circ} \mathrm{C}$ at $2^{\circ} \mathrm{C} / \mathrm{min}$ and nitrogen as carrier gas for the FID at $60^{\circ} \mathrm{C}$ as oven temperature. GCMS-QP 2010 Ultra- Shimadzu GC-2010 Plus consist of capillary column made$\mathrm{u}$ of Frontier Labs UA+-65 (30 $\mathrm{m} \times 0.25 \mathrm{~mm}$ I.D. $\mathrm{df}=0.1 \mu \mathrm{m})$, which was maintained at temperature: $150^{\circ} \mathrm{C}$ (for $1 \mathrm{~min}$ ) and ramped at 5 ${ }^{\circ} \mathrm{C} / \mathrm{min}$ upon $320{ }^{\circ} \mathrm{C}$ (for $20 \mathrm{~min}$ ). The injection and FID temperature was 300 and $320{ }^{\circ} \mathrm{C}$, the split ratio was $1 / 100$ and $m / z$ intensity range was 20.00-800.00.

The constructive interference of crystal or phase structure can be identified by monochro- matic X-ray beam scattering. The uniform or skeletal spacing in crystals are identified by creating the patterns of waves in incident Xrays diffraction (XRD) scattering. XRD patterns of the prepared dried solid catalyst are measured using $\mathrm{Cu} \mathrm{K} \alpha(\lambda=1.54 \AA)$ and Mo-K $\alpha$ $(\lambda=0.71 \AA)$ radiation in miniflex and smart-lab Rigaku diffractometer where the sample crystalline structure have analysed at the range of 5 to $70^{\circ}$ of 2 -theta with a scan step of $0.05^{\circ}$ and this performed a counting time of $4 \mathrm{~s}$ for each step.

The Scanning Electron Microscope (SEM) had operated at an acceleration voltage of 30 $\mathrm{kV}$. Usually, the samples are used at room temperature after vacuum and dried at $250{ }^{\circ} \mathrm{C}$ for 2.5 hours. Before sent to analysis, sample materials are grained into powder in ethanol solution and involved at vacuum-dried condition on $120^{\circ} \mathrm{C}$ for $3-4$ hours. After drying, the material has to be placed for identification of grain orientation and texture analysis on an electron backscattered diffraction detector.

The Brunauer, Emmet, and Teller (BET) surface area has been investigated by Quanta Chrome Nova-1000 surface analyzer instrument under liquid nitrogen temperature. During each measurement, the samples are degassed at $300{ }^{\circ} \mathrm{C}$ for 24 hours to remove moisture and unwanted absorbed gases in the surrounding.

Fourier-Transform Infrared Spectroscopy (FTIR) with specification of Bruker FTIR A. Model Tensor-27 was used for solid catalyst acidity measurement. Here, $5 \mathrm{gm}$ of solid sample, which is dried in vacuum chamber at 350 ${ }^{\circ} \mathrm{C}$ for 4 hours, has been made as thin wafers by pressed in coin shape by placing in the IR cell. Then, pyridine vapour at $200{ }^{\circ} \mathrm{C}$ has introduced to the cell for $60 \mathrm{~min}$ and then, the cell was placed at hot inert gas $\left(\mathrm{N}_{2}\right)$ which has passed to record the spectrum. Mode of interpretation is transmission and wavenumber $\left(\mathrm{cm}^{-1}\right)$ in the acidity validation graph.

\section{Result and Discussion}

The composition, temperature, holding time and nature of the reactants are the major parameters which have to investigate the solid catalyst performance over hydrotreating and branching of the feed. Here, the study mainly focused on the performance of the Pt/SAPO-11 by varying the temperature and pressure of the reactor with constant flow of reactant and its composition of the sunflower oil.

The synthesised catalyst, Pt/SAPO-11, was analysed and tested for uniform pore distribu- 
tion, acidic site and particle size using various testing methods such as BET, SEM analysis, FTIR and XRD. To identify and study the crystallinity of the SAPO-11 produced, the support material are examined in SEM and XRD analysis for the understanding. Also, the acidity on the surface metals of support is investigated by Pyridine-FTIR analysis.

The experimentation of the catalytic hydrotreating of the vegetable oil (Sunflower oil) using the synthesized support impregnated with
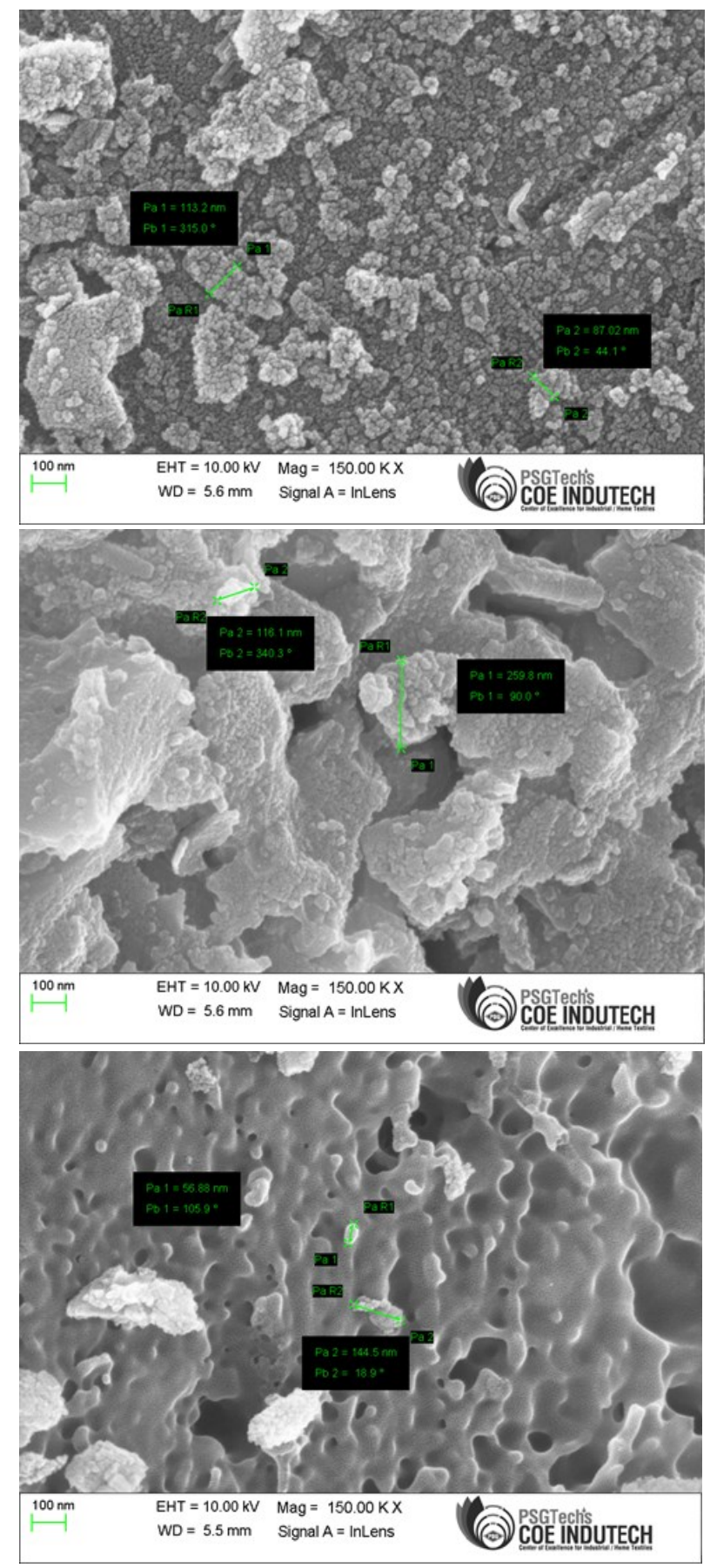

Pt metal. $31 \mathrm{~mL}$ (27.83 gm) of Pt/SAPO-11 material (with exact weight of $27.59 \mathrm{~g}$ catalyst) is loaded in the reactor, activated using fresh $\mathrm{H}_{2}$ at $350{ }^{\circ} \mathrm{C}$ for 4 hours and the investigation on the catalyst performance at space velocity of unity with respect to $31 \mathrm{ml}$ of sunflower oil pumped into the reactor has performed. The space velocities are calculated at liquid hourly space velocity (LHSV $=\mathrm{mL}$ of liquid $/ \mathrm{mL}$ of cat. $\left.{ }^{*} \mathrm{~h}\right)$ or (also represented as $\mathrm{h}^{-1}$ ) at preferred reaction pressure (1 to $3 \mathrm{MPa}$ ) and reaction
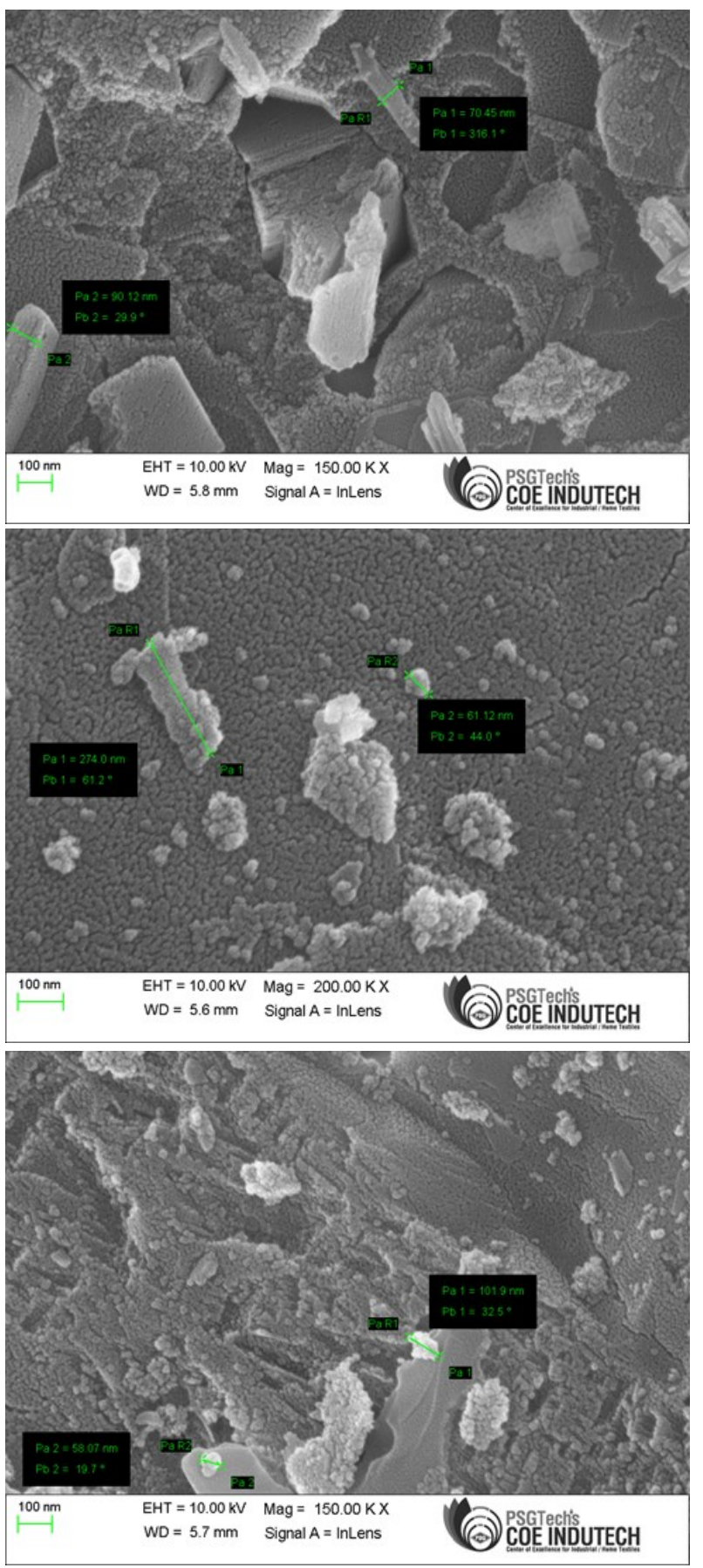

Figure 2. SEM images of SAPO-11 prepared by using (a) n-propylamine U + H, (b) n-propylamine U, (c) dimethylamine $\mathrm{U}+\mathrm{H}$, (d) dimethylamine $\mathrm{U}$, (e) diethylamine $\mathrm{U}+\mathrm{H}$, and (f) diethylamine $\mathrm{U}$. 
temperature $\left(290\right.$ to $\left.360{ }^{\circ} \mathrm{C}\right)$. So, the experiment started with $31 \mathrm{~mL}$ of catalyst with corresponding $1 \mathrm{~h}^{-1} \mathrm{LHSV}$ is performed in a continuous fixed-bed reactor. Also, the tolerance error for mass balances of lighter hydrocarbons and some middle distillate fractions are considered within approximated range of 0.5 to $1 \mathrm{wt} \%$. In addition, traces at the samples of heavy hydrocarbons beyond $\mathrm{C} 19$ are considered to be negligible. So, the main components in the residual products are hydrocarbons from dodecane to heavy hydrocarbons $(\mathrm{C} 18 \leq)$ and also included with traces of lighter hydrocarbons.

\subsection{Microscopic Analysis}

The SEM analysis has performed for the synthesized SAPO-11 materials to understand the structure of the sample. It is observed that the sample synthesised with n-propylamine (nPA) as template under ultrasonic with hydrothermal method (UH) combined together as named as $\mathrm{S}-1$, the particles are observed with a uniform globules having an average particle size of $100.12 \mathrm{~nm}$, as represented in Figure 2 (a). The structure has identified to be irregular which is related to its heterogeneous morphology. Further, while the sample with same template (n-PA) synthesized under ultrasonication process (S-2), exhibit sharp edges of nonuniform cuboids (Figure 2 (b)). The crystal structure in this sample is non-uniform in size and shape. This non-uniform structures show an average particle size of $80.29 \mathrm{~nm}$. Whereas in the sample produced with dimethylamine (DMA) as a template under UH combined together (S-3) have exhibited irregular surface morphology. Thus, it has large body like structures with irregular hollow pits spread along the surface of the body, as shown in Figure 2 (c). The hollow pits seen on the surface indicates that incomplete crystal growth has occurred. The average particle size of the pro- duced sample is $187.96 \mathrm{~nm}$. But the particle size is larger and if there is incomplete formation of structure, the sample produced will have a negative effect on lifetime. In the sample of dimethylamine as template under ultrasonic process with hydrothermal treatment (S4), Figure 2 (d) observed that there is a formation of few non- uniform clumps of small sized bodies. The small sized bodies formed are irregular in shape and size. These irregular bodies are formed over the surface of support base of S-4 with the average particle size of $167.55 \mathrm{~nm}$.

In the sample synthesized with diethylamine (DEA) as a template under ultrasonication and hydrothermal treatment (UH) coupled together (S-5), Figure 2 (e) observed that there is no proper crystal growth within tested condition. The pores are non-uniform and the morphology is irregular to the subjected synthesis process. The SEM images represent that there a few clusters of irregular shaped bodies with incomplete crystal growth. The average particle size represent in this sample is around $100.69 \mathrm{~nm}$. Whereas, sample of diethylamine (DEA) as a template synthesized under ultrasonic process without hydrothermal treatment (S-6), the Figure 2 (f) shows that there is formation of small sized spherical bodies which has heterogeneous morphology. It is observed that the spherical structures in this sample have just initiated to form flakes. However, the corners of the flakes have figured to catch the pictures of original shapes rather than the entire flake. The average particle size of this sample is found to be $79.99 \mathrm{~nm}$. Table 1 enlists the detailed information of the particle size of the material synthesized from different combinations and template in the method of material synthesis. The smaller particle size in the ultrasonically prepared samples can be accounted to the reduction in agglomeration of the cell crystals rather giving a rise in nucleation and

Table 1. Average Particle size of the synthesized SAPO materials and the data is extracted from Figure 2.

\begin{tabular}{lccccc}
\hline $\begin{array}{c}\text { Sample with } \\
\text { sample no. }\end{array}$ & Template & Synthesis & Pa 1 (nm) & Pa 2 (nm) & $\begin{array}{c}\text { Average Size } \\
(\mathrm{nm})\end{array}$ \\
\hline n-PA (UH) (S-1) & n-PA & U+H & 87.02 & 113.2 & 100.12 \\
n-PA (U) (S-2) & n-PA & U & 70.45 & 90.12 & 80.29 \\
DMA (UH) (S-3) & DMA & U+H & 116.1 & 259.8 & 187.96 \\
DMA (U) (S-4) & DMA & U & 61.12 & 274 & 167.55 \\
DEA (UH) (S-5) & DEA & U+H & 56.88 & 144.5 & 100.69 \\
DEA (U) (S-6) & DEA & U & 58.07 & 101.9 & 79.99 \\
\hline
\end{tabular}


crystal growth. In turn this accounts for the rise in crystallinity [19].

\subsection{XRD Analysis}

The phase purity and crystallinity of the samples are determined by using Powder X-ray diffraction (XRD) patterns. Crystallinity characterization of the samples has calculated by the equation [20].

$$
\text { Relative intensity }=\frac{\text { Intensity }}{\text { Reference Intensity }}
$$

The line intensities of the XRD pattern at $2 \theta$ equal to $21.5,45.7,59.9$ and $67.2^{\circ}$ are employed for these calculations.

The X-ray diffraction patterns of SAPO-11 samples prepared by two methods are respectively shown in Figure 3. The high intensity of the XRD lines and the low background in the XRD pattern indicate the high crystallinity of the samples and, also the decrease in the intensity of the XRD peaks indicates the probable loss in crystallinity. It can be observed that all these structures are the same and have similar peak positions at Bragg angle $2 \theta=21.5,45.7$, 59.9 and $67.2^{\circ}$. The characteristic diffraction peak at $2 \theta=21.5^{\circ}$ are in agreement with that of SAPO-11 zeolite framework [21-23]. The intense peaks at a Bragg angle $2 \theta$ of $21.5^{\circ}$ confirm the preferred orientation to the c-axis of hexagonal crystals. The crystallinity of the S-2 catalyst has found to be higher than the other catalysts. So, this has been considered as the

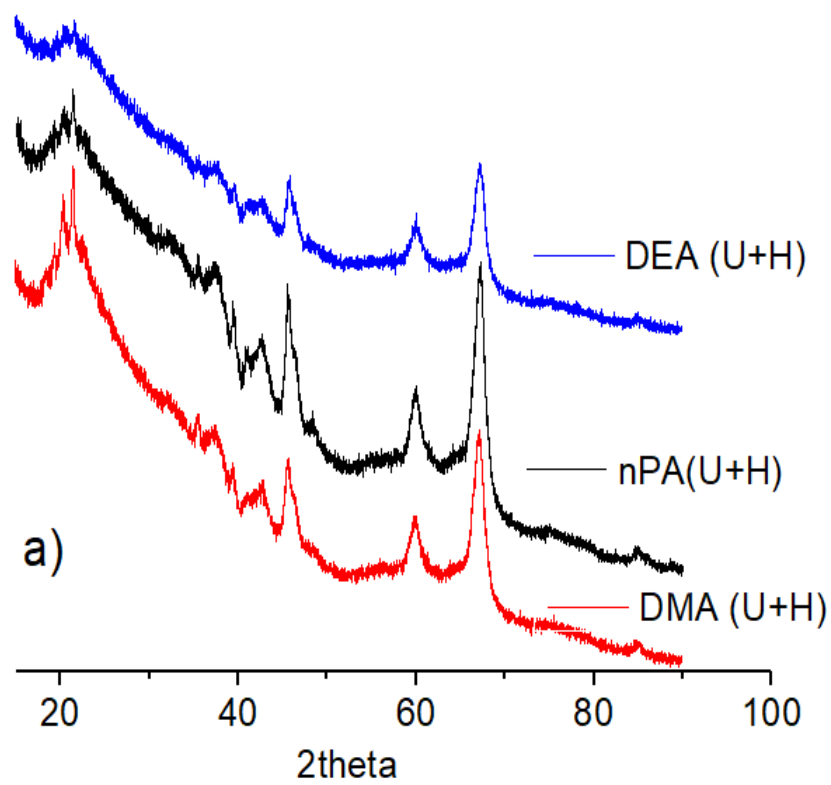

reference data while determining the crystallinity of other samples. It is found that the relative crystallinity of all catalysts related to the formation of SAPO-11 phase have decreased in the following order:

$$
\begin{aligned}
& \text { n-PA }(\mathrm{U})>\text { DMA }(\mathrm{U})>\text { DEA }(\mathrm{U})>\text { n-PA }(\mathrm{UH})> \\
& \text { DMA }(\mathrm{UH})>\text { DEA }(\mathrm{UH}) .
\end{aligned}
$$

The diffraction peak intensities or crystallinity of SAPO-11 catalyst synthesized by ultrasonication is generally higher than that of the catalysts synthesized using ultrasonication in hydrothermal condition, which suggests that the ultrasonic coupled with hydrothermal synthesis is more effective for the catalyst synthesis. At low temperature and short period of residence time, ultrasonic transformation is capable of synthesizing catalysts with higher degree of crystallinity. In addition, the reflections of peaks are found to be greater for n-propyl amine than the other two catalysts and diethylamine template can demonstrates the lowest peak intensity in the material validation. The higher crystallinity observed with the ultrasonically synthesized samples is due to the boosted crystal growth and higher external specific surface area.

\subsection{FTIR Analysis}

The acidity of the zeolites has examined by using Pyridine-FTIR analysis, as represented in Figure 4 . The notable bands for the acidic

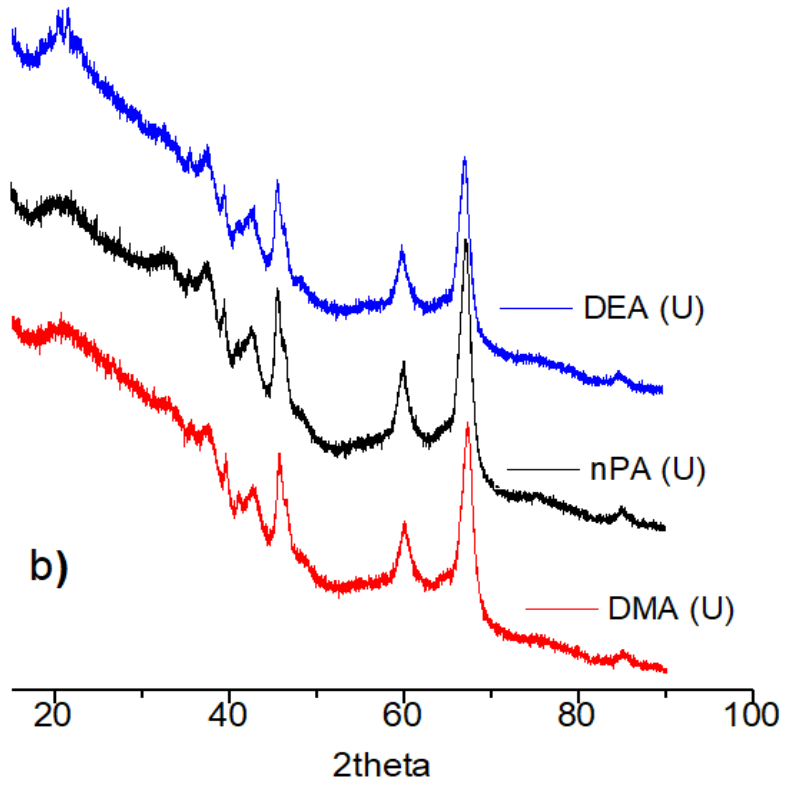

Figure 3. XRD images of SAPO-11 prepared by using a) ultrasonic assisted hydrothermal synthesis $(\mathrm{UH})$ method and b) Ultrasonic synthesis $(\mathrm{U})$ method [Note: $\mathrm{n}-\mathrm{PA}=\mathrm{n}$-propylamine template, DME= dimethylamine and DEA= diethylamine]. 
sites in the pyridine adsorption on the surface of metal site and hydrates present on the surface of metal and oxides are investigated using FTIR. It is observed that the bands occur at wavenumbers around 1400, 1545, 1636, and $3450 \mathrm{~cm}^{-1}$ on both plots of FTIR analysis of samples synthesized by hydrothermal treatment and ultrasonication process are indicated in Figure 4 (a-c). Transmittance percentage exhibited by the sample prepared by ultrasonic
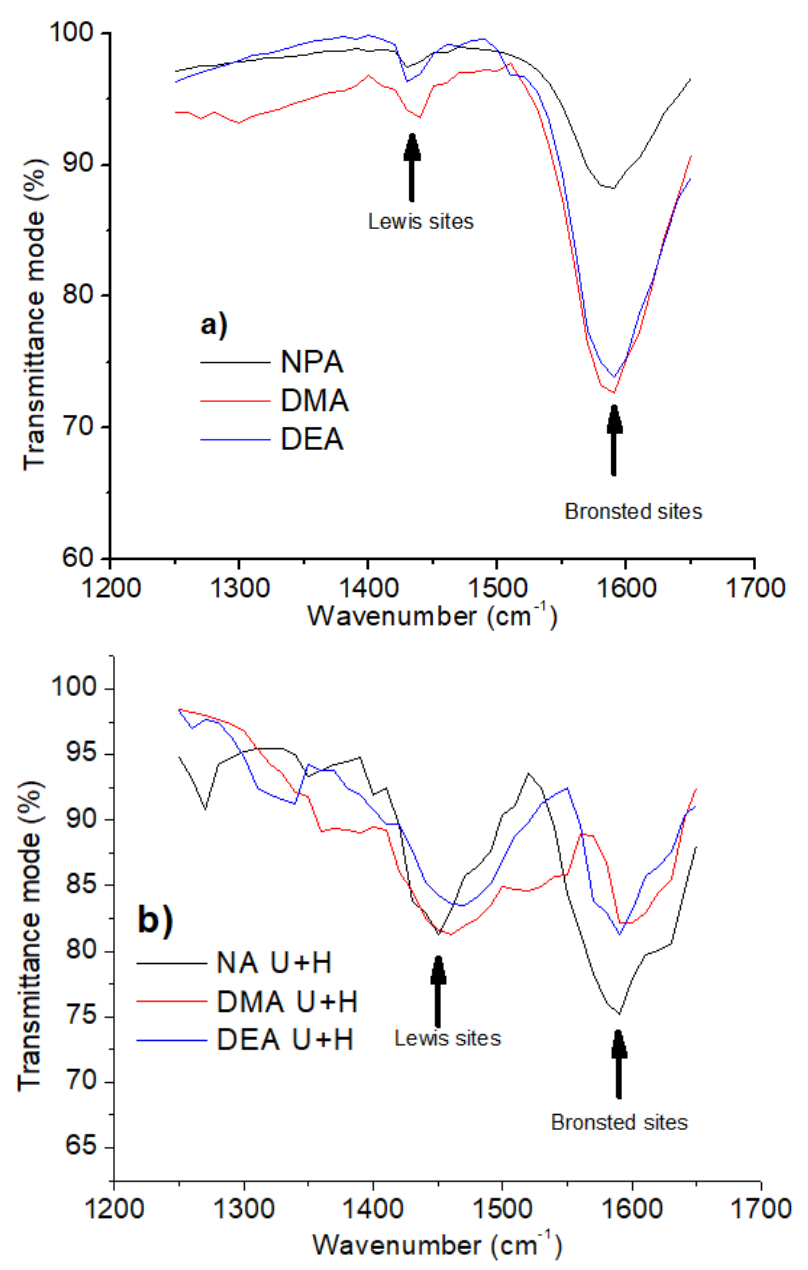

with hydrothermal condition is higher than the other samples. Peaks occurring at $1400 \mathrm{~cm}^{-1}$ exhibit Lewis acidity and as the wavenumber increases in $1493 \mathrm{~cm}^{-1}$, Bronsted acidity has initiated to add up with the Lewis acidity. At wavenumber of $1545 \mathrm{~cm}^{-1}$, it is comprised mainly of Bronsted acidity [24-27].

Between 1200 and $1000 \mathrm{~cm}^{-1}$, specific high intensity band at $1068 \mathrm{~cm}^{-1}$ has identified as a distinct feature in the very broad and high intensity band on below $1000 \mathrm{~cm}^{-1}$, the absorption is represented with high intensity that no evaluation of band positions are possible. The acidic peaks are represented in the Figure 4 (a) and (b). The asymmetric stretching vibration at wavenumber of $2080 \mathrm{~cm}^{-1}$ is assigned to the physically adsorbed $\mathrm{CO}_{2}$. The stretching vibration at wavenumber $1636 \mathrm{~cm}^{-1}$ can be assigned to the $\mathrm{H}-\mathrm{O}-\mathrm{H}$ weakly adsorbed in SAPO-11 $[28,29]$. The spectrum in the $\mathrm{OH}$ region-except for the polarization which hasn't been reported before is well in accordance with literature data obtained from the analysis of powdered polycrystalline samples, recorded in either transmission or diffuse reflectance.

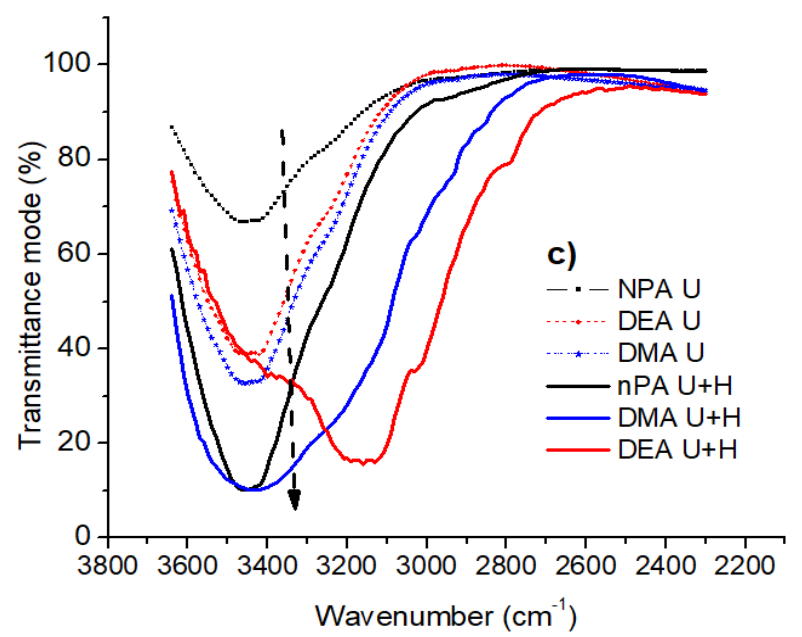

Figure 4. FT-IR images of SAPO-11 prepared by using (a) Ultrasonication, (b) Ultrasonication and hydrothermal and (c) hydroxyl-group in catalyst. Note- At (c), Dotted Arrow represents the increase in intensity of the spectrum for $-\mathrm{OH}$ group.

Table 2. Surface area of the catalyst produced by different methods with various templates (Surface area of the catalyst produced by different methods with various templates).

\begin{tabular}{lccccc}
\hline \multicolumn{1}{c}{ Sample } & Template & $\begin{array}{c}\text { Mean pore } \\
\text { diameter }(\mathrm{nm})\end{array}$ & $\begin{array}{c}\text { Total pore } \\
\text { volume }\left(\mathrm{m}^{3} / \mathrm{g}\right)\end{array}$ & $\begin{array}{c}\text { Vm } \\
\left(\mathrm{cm}^{3}(\mathrm{STP}) / \mathrm{g}\right)\end{array}$ & $\begin{array}{c}\text { Surface area } \\
\left(\mathrm{m}^{2} / \mathrm{g}\right)\end{array}$ \\
\hline n-PA (UH) (S-1) & n-PA & 10.05 & 156.63 & 12.52 & 474.88 \\
n-PA (U) (S-2) & n-PA & 9.37 & 72.85 & 10.75 & 682.52 \\
DMA (UH) (S-3) & DMA & 11.21 & 122.53 & 14.58 & 493.74 \\
DMA (U) (S-4) & DMA & 9.82 & 67.13 & 11.01 & 731.38 \\
DEA (UH) (S-5) & DEA & 11.88 & 107.82 & 13.35 & 396.51 \\
DEA (U) (S-6) & DEA & 9.85 & 61.25 & 11.41 & 737.80 \\
\hline
\end{tabular}


The spectra of the samples in the $\mathrm{OH}$ stretching vibration domain are shown in Figure 4 (c). The vast band stretching across the range 3000 to $3600 \mathrm{~cm}^{-1}$ can be attributed to the hydroxyl groups from the $\mathrm{Si}-\mathrm{OH}-\mathrm{Al}$ bond [30,31].

\subsection{Particle Size Analysis}

Table 2 shows the surface area of the synthesized SAPO-11 catalysts under ultrasonic method and ultrasonic assisted hydrothermal methods together. The surface area is obtained from the Brunauer-Emmett-Teller (BET) analysis. The results are attained for the samples with the use of different types of templates such as n-propylamine (n-PA), dimethylamine (DMA) and diethylamine (DEA).

From the data shown in the Table 2, it is observed that the samples synthesized using $n$ propylamine as template has a medium surface area when compared to the other SAPO-11 materials obtained. The SAPO-11 based-catalyst under ultrasonic and hydrothermal methods together with n-PA as template (S-1) has a pore volume of $156.63 \mathrm{~m}^{3} \cdot \mathrm{g}^{-1}$. From the Table 2 , it is clearly visible that this sample has the highest pore volume when compared to the other synthesized samples. The Figure 5 indicates the sampling adsorption isotherm on n-PA of both S-1 and S-2 for the indication. The sample produced under ultrasonic method with n-PA as template (S-2) has a pore volume of 72.85 $\mathrm{m}^{3} \cdot \mathrm{g}^{-1}$.

From the results obtained from the BET analysis, it is seen that the sample produced with dimethylamine (DMA) as template under ultrasonic and hydrothermal methods combined together (S-3) has a pore volume of $122.53 \mathrm{~m}^{3} \cdot \mathrm{g}^{-1}$. It is also observed that the sample produced under the same DMA template on ultrasonic condition (S-4) has a pore volume of $67.13 \mathrm{~m}^{3} \cdot \mathrm{g}^{-1}$.

Further, it is analysed from the BET results obtained that the sample produced with the help of diethylamine (DEA) as template under both ultrasonic and hydrothermal conditions coupled together (S-5) has a pore volume of $107.82 \mathrm{~m}^{3} \cdot \mathrm{g}^{-1}$. Similarly the sample obtained with the help of the same template (DEA) under ultrasonic method (S-6), has pore volume of $61.25 \mathrm{~m}^{3} \cdot \mathrm{g}^{-1}$. It is noticed from the results obtained from the BET data that the sample produced with the diethylamine (DEA) as template under ultrasonic and both hydrothermal and ultrasonic conditions combined together has the lowest surface area when compared to other samples produced with n-propylamine (nPA) and dimethylamine (DMA) as templates. The pore volume of the samples produced with the above mention templates decreased in the order of $\mathrm{n}-\mathrm{PA}>\mathrm{DMA}>\mathrm{DEA}$.

\subsection{Hydrodeoxygenation of Sunflower Oil}

The synthesized catalyst is investigated in hydrotreating of triglyceride compounds in trickle-bed reactor with LHSV $=1 \mathrm{~h}^{-1}$. The carbonic compound in oxygenated group of triglycerides at sunflower oil is removed as $\mathrm{CO}_{2}, \mathrm{CO}$, and $\mathrm{H}_{2} \mathrm{O}$ within represented mechanism such as Decarboxylation (DCO), Decarbonylation

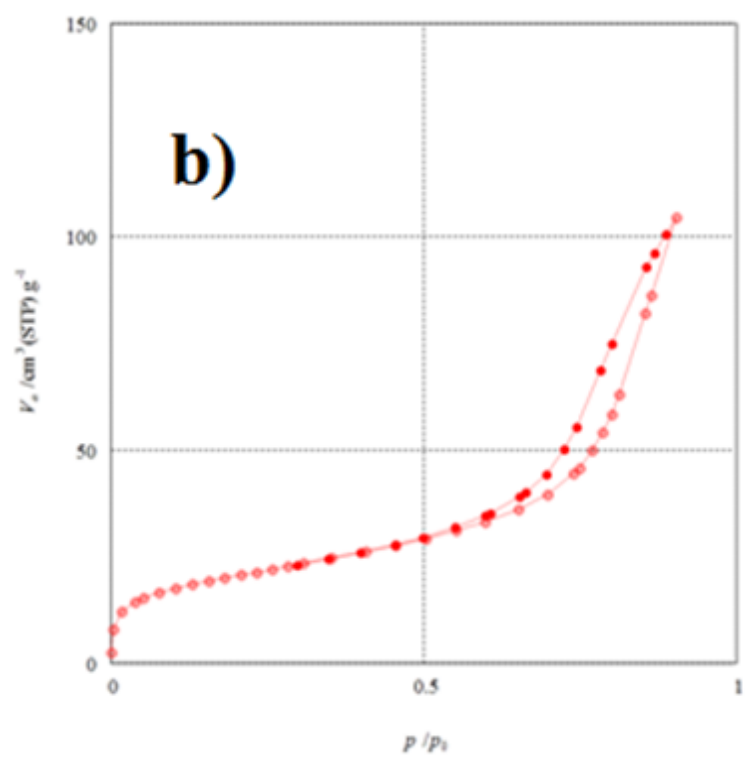

Figure 5. a) Hydrothermal synthesis of SAPO with n-Propylamine templates and b) Ultrasonic synthesis of SAPO for 6 hour at $60^{\circ} \mathrm{C}$ at $20 \mathrm{kHz}$. 
(DCA), and Hydrodeoxygenation (HDO), respectively with paraffins as their main products with a wide range of carbon numbers [3235]. Table 3 enlists the data on operating conditions for the hydrodeoxygenation of sunflower oil along with the conversion, selectivity, and product composition for the synthesized SAPO11 with Pt, the GC-MS results of the hydrodeoxygenation is represented in Figure 6. Here, the results obtained using the synthesized Pt/SAPO-11 catalyst samples are also compared with the obtained commercial zeolites which is named as $\mathrm{H}-\beta$ catalyst with $\mathrm{Pt}$ on surface. Though H- $\beta$ material is popular in high thermal stability material and high cracking of hydrocarbon, it has wide application in the fuel upgrading at the refinery process.

From the this investigation, it is found that the catalysts prepared under ultrasonic (U) method are superior to that synthesized by the other method (UH) in terms of crystallinity and acid sites distribution. Hence detailed studies on the ultrasonically synthesized catalysts samples are carried by changing the operating temperature and pressure of hydrotreating process with existing catalyst on appropriate conditions. By all comparison as shown in the Table 3, the results obtained using synthesized Pt/SAPO-11 samples exceeded and represent with high conversion rate while compared to the commercial catalyst (H- $\beta)$. Also, the role of $\mathrm{Pt}$ on the catalyst is assumed to have same characteristic and function for this investigation. For n-PA (UH) samples, the conversion efficiency increased with the increase in operating temperature, while maintaining the operating pressure constant, characterized $\mathrm{C} 17$ and C18 compositions are identified by GC-MS in Figure 6 for corresponding operating temperature. The lighter hydrocarbon and middle distillate formation is noticed in the Figure 6. However, there is a drop in the yield of monobranched products with the tested condition. When the investigation has repeated with maintained constant operating temperature and while varying the pressure, the conversion efficiency increased with an increase in the yield percentage of mono-branched products

Table 3. HDO of sunflower oil in reactor at LHSV $=1 \mathrm{~h}^{-1}$.

\begin{tabular}{|c|c|c|c|c|c|c|c|c|}
\hline Sample & Template & $\begin{array}{l}\text { Oper. } \\
\text { Temp. } \\
\left({ }^{\circ} \mathrm{C}\right)\end{array}$ & $\begin{array}{l}\text { Oper. } \\
\text { Press. } \\
(\mathrm{MPa})\end{array}$ & $\begin{array}{c}\text { Conversion } \\
\text { (\%) }\end{array}$ & $\begin{array}{c}\text { Selectivity } \\
\text { HDO/(DCO+DCA) }\end{array}$ & $\begin{array}{c}\text { Mono- } \\
\text { branched } \\
(\%)\end{array}$ & $\begin{array}{c}\text { Di- } \\
\text { branched } \\
(\%) \\
\end{array}$ & $\begin{array}{l}\text { Cracked } \\
\left(<\mathrm{C}_{8}\right)(\%)\end{array}$ \\
\hline$H-\beta$ & & 320 & 2 & 81 & 1.1 & 46 & 14 & 40 \\
\hline S-1 & n-PA (UH) & 320 & 2 & 91 & 1.5 & 55 & 15 & 30 \\
\hline \multirow{6}{*}{$\mathrm{S}-2$} & \multirow{6}{*}{ n-PA (U) } & 300 & 2 & 84 & 1.3 & 67 & 13 & 20 \\
\hline & & 320 & 2 & 92 & 1.2 & 63 & 22 & 15 \\
\hline & & 340 & 2 & 98 & 1.5 & 57 & 21 & 22 \\
\hline & & 320 & 1.5 & 92 & 1.1 & 55 & 18 & 27 \\
\hline & & 320 & 2.5 & 94 & 1.5 & 61 & 22 & 27 \\
\hline & & 320 & 3 & 95 & 1.6 & 66 & 22 & 21 \\
\hline S-3 & DMA (UH) & 320 & 2 & 84 & 1.4 & 52 & 13 & 35 \\
\hline \multirow{6}{*}{ S- 4} & \multirow{6}{*}{ DMA (U) } & 300 & 2 & 71 & 1.3 & 51 & 9 & 40 \\
\hline & & 320 & 2 & 82 & 1.5 & 52 & 12 & 36 \\
\hline & & 340 & 2 & 89 & 1.5 & 55 & 14 & 31 \\
\hline & & 320 & 1.5 & 84 & 1.5 & 52 & 15 & 33 \\
\hline & & 320 & 2.5 & 91 & 1.6 & 56 & 17 & 27 \\
\hline & & 320 & 3 & 93 & 1.6 & 59 & 18 & 23 \\
\hline S-5 & DEA (UH) & 320 & 2 & 88 & 1.4 & 53 & 12 & 35 \\
\hline \multirow{3}{*}{ S- 6} & \multirow{3}{*}{ DEA (U) } & 300 & 2 & 78 & 1.1 & 72 & 11 & 17 \\
\hline & & 320 & 2 & 88 & 1.3 & 62 & 17 & 21 \\
\hline & & 340 & 2 & 96 & 1.5 & 56 & 19 & 25 \\
\hline
\end{tabular}


and it is observed that $\mathrm{HDO} /(\mathrm{DCO}+\mathrm{DCA})$ ratio also increases constantly and linearly concurs with the literature fact that $\mathrm{DCA} / \mathrm{HDO}$ ratio decreases as temperature increases [36-39]. The DCO and DCA mechanism forms C16 and C17 hydrocarbons, whereas $\mathrm{C} 18$ can be formed by HDO mechanism. The conversion efficiency peaked for both n-PA (UH) and DEA (UH) on the operating condition of $\mathrm{T}=340^{\circ} \mathrm{C}$ and $\mathrm{P}=2$ $\mathrm{MPa}$. Using DMA (UH) sample, the conversion peaked at operating conditions of $\mathrm{T}=320{ }^{\circ} \mathrm{C}$ and $\mathrm{P}=3 \mathrm{MPa}$. Unlike the other side processes, selectivity for hydrodeoxygenation is observed to be expressed as a drastic rise of $\mathrm{C} 17$ with increase in the operating pressure for the investigated experiments as indicated in between 10 to 11 mins of retention time at GC-MS.

\subsection{Hydroisomerisation of n-Octadecene}

The HDO of sunflower oil contains unsaturated double bonds of triolein, trilinolein, tripalmitin, and tristearin triglycerides in the sunflower oil. These higher level unsaturated triglycerides demand higher consumption of hydrogen on hydrotreatment i.e., HDO pathway [35-40].

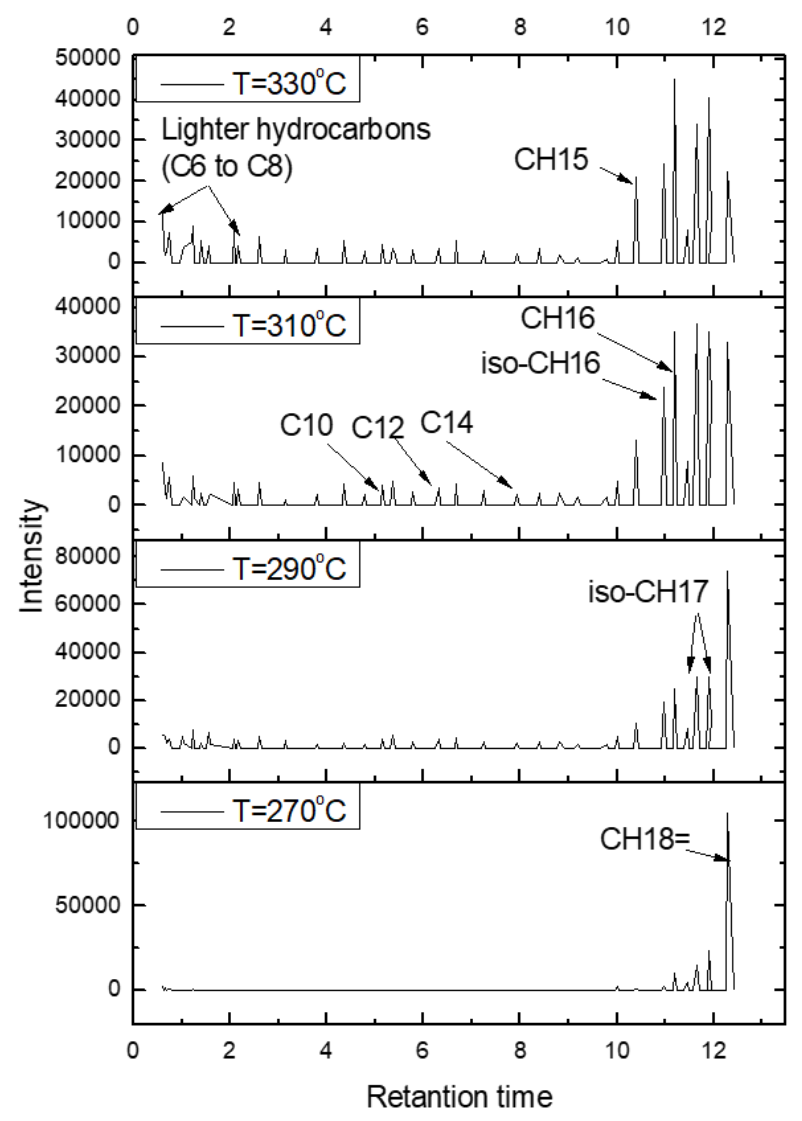

Figure 6. GC analysis of hydroisomerisation of $\mathrm{n}-\mathrm{C} 18=$ using Pt/SAPO and $5 \mathrm{MPa}$.
In this study, we used a gas chromatography-mass spectrometry (GC-MS) analysis (Figure 6) to determine the presence of the paraffin in the end product. Figure 7(a) displays the variation in concentration in products ( $\mathrm{wt}$ $\%)$ over varying operating temperature at constant LHSV $=1 \mathrm{~h}^{-1}$ and 5.0 $\mathrm{MPa}$. The results from both these tests are found to be in consensus with each other and the interpretations are given as following:

Peaks beyond the retention time $12 \mathrm{~min}$ in the Figure 6 and higher depiction of hydrocarbons with boiling point above $300{ }^{\circ} \mathrm{C}$ in Figure 7 (a) are appeared due to the feed subjected by octadecene (n-C18=) paraffin. The fairly elevated presence of these traits at the operating temperature $270{ }^{\circ} \mathrm{C}$ establishes that the hydro-
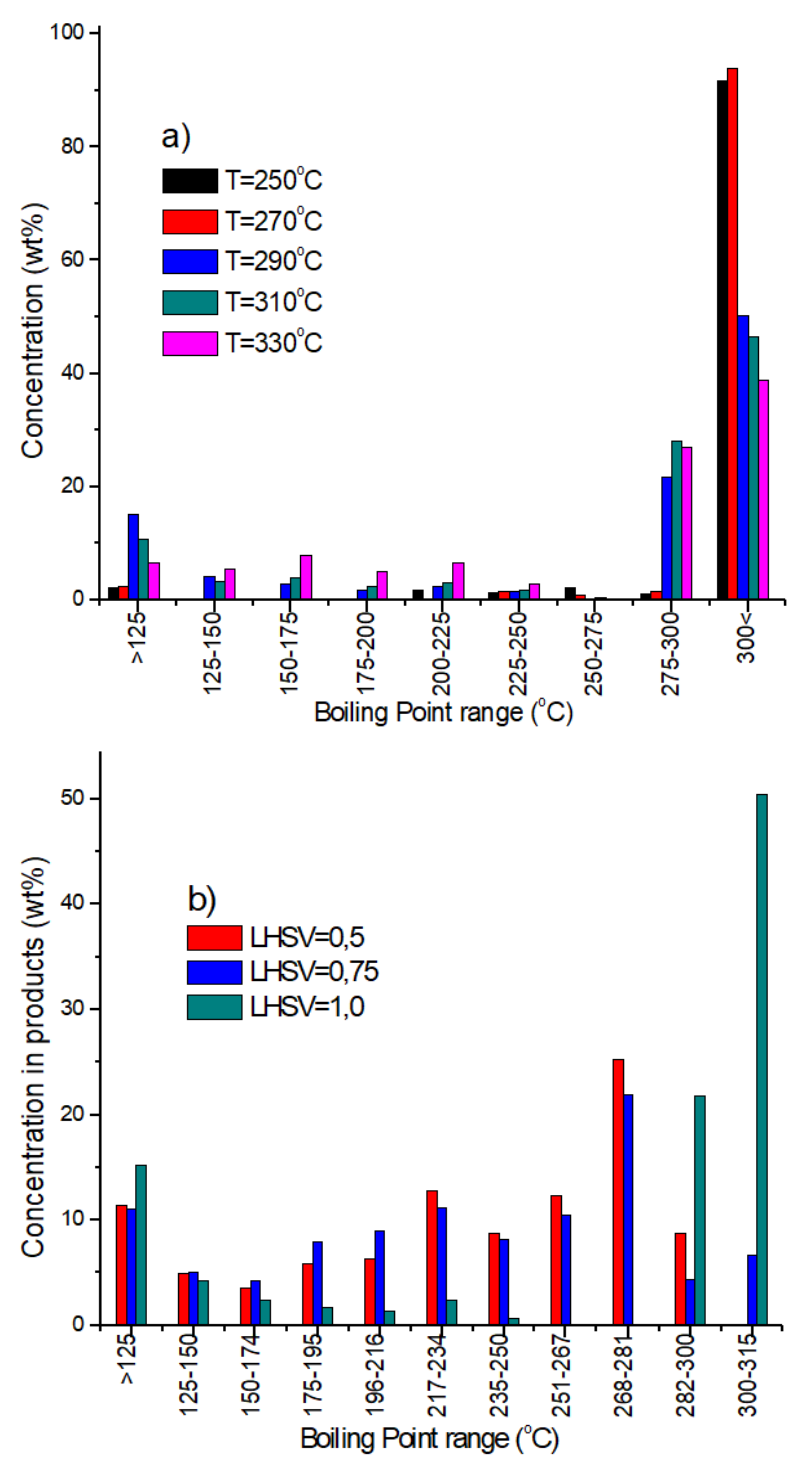

Figure 7. Hydro-isomerisation of $\mathrm{n}-\mathrm{C} 18=$ of a) different operating temperature and $5 \mathrm{MPa}$ and b) different space velocity of feed at $\mathrm{T}=$ $310^{\circ} \mathrm{C}$ and $5 \mathrm{MPa}$. 
a)<smiles>CCCCC(=O)OCC(CCCC)COC(=O)CCC(C)(C)C</smiles>

Tristearin

b)

\section{Cracking}<smiles>[R1]CCC=C</smiles>

Heptadecene<smiles>[R1]CC=C</smiles>
Octadecene $\quad \| \mathrm{H}^{+} \quad \mathrm{R} 1 \Longrightarrow \mathrm{CH}_{3}-\left(\mathrm{CH}_{2}\right)_{12}-$<smiles>CC(C)(C)C(=O)O</smiles><smiles>CC(C)C=O</smiles>

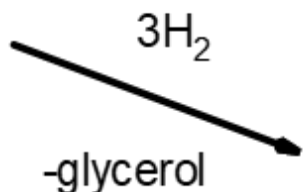

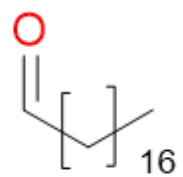<smiles>[R1]CCCC=C</smiles><smiles>[R1]CCC[CH+]C</smiles><smiles>O=CCCC(=O)O</smiles><smiles>[H]</smiles>

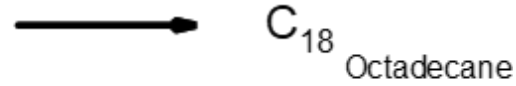

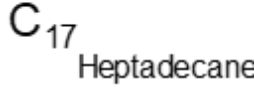<smiles>C1CCC1</smiles>

$\mathrm{R} 1$

$$
\| \mathrm{H}^{+}
$$

Hexadecene<smiles>[R]=C</smiles>

Tetradecene
R1<smiles>C[CH+]CCCC</smiles><smiles>[R]C[C+]([CH+]C)CCC</smiles><smiles>[R]C[C+]([CH+]C)CCC</smiles><smiles>[C+]1CC1</smiles>

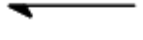

Pentadecene

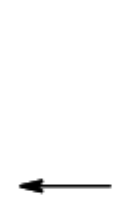

3-methyl heptadecane

Branching<smiles>[R1]</smiles><smiles>CC(C)CCI</smiles>

2-methyl heptadecane<smiles>[R1]CC(C)CC</smiles>

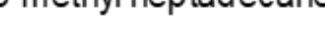

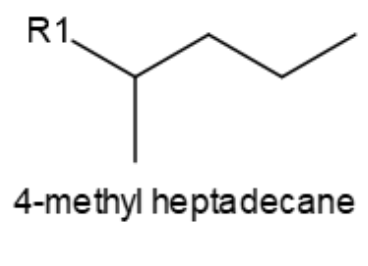
4-methyl heptadecane

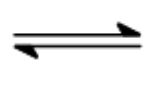

Figure 8. Proposed mechanism of a) Hydrodeoxygenation of triglycerides into hydrocarbons and b) Hydro-isomerisation of $\mathrm{n}-\mathrm{C} 18=$ into branched hydrocarbons. 
genolysis is initiated at its preliminary heating stage. The distortion in between retention times 10 and 12 seconds in the following processes with operating temperature above 270 ${ }^{\circ} \mathrm{C}$ are attributed to the hydro-isomerized products of the $\mathrm{n}-\mathrm{C} 18=$ hydrocarbon whose boiling points falls in the range of $275-300{ }^{\circ} \mathrm{C}$. An abrupt increase in the peaks below the retention time 2 seconds when processed at temperatures above $310{ }^{\circ} \mathrm{C}$ corresponds to the low boiling pointed alkanes ranging from $\mathrm{C} 8$ to $\mathrm{C} 16$. This is attributed on the account of undesirable hydrocracking taking place at higher operating temperatures. Detailed hydroprocesssing and hydroisomerisation of this mechanism is represented in Figure 8 (a) and (b).

The numeric data of the GC-MS Analysis is provided in the Table 4. Conversion as well as the composition of both iso-alkanes and nalkanes shows a significant increase with increasing operating temperatures. An increase in iso-alkanes is desirable reaction but the undesirable escalation in n-alkanes is due to the cracking which also contributes to the decline in the ratio of isomerization to cracking. Augmentation in this ratio may result in blocking of pores and a prominent acceleration in the degradation of catalyst life. Thus, with increase in temperature, the rate of conversion increased which is also accompanied with cracking at higher temperature and lowered selectivity to iso-paraffins.

Study on the effect of LHSV on the hydroisomerization reaction is also studied altering the LHSV rate at constant temperature $310{ }^{\circ} \mathrm{C}$ and pressure $5 \mathrm{MPa}$ and the results are shown in Figure 7(b). At low LHSV $0.5 \mathrm{~h}^{-1}$, presence of $\mathrm{n}-\mathrm{C} 18$ was found to be a relatively negligible amount when compared to its presence at higher velocities. Adding on with point that the products with boiling point range falling between 268 and $281{ }^{\circ} \mathrm{C}$, higher conversion rate was confirmable. At $0.75 \mathrm{~h}^{-1} \mathrm{LHSV}$, conversion was good but with a small observable amount of C18 hydrocarbons falling in the boiling point range 300 and $315{ }^{\circ} \mathrm{C}$. At $1.0 \mathrm{~h}^{-1} \mathrm{LHSV}$, the conversion is lower that it showed a higher intensity peak at the concentration of $\mathrm{C} 18$ hydrocarbons. So, at given temperature and pressure, hydro-isomerization is favoured at a considerably lower LHSV.

\section{Conclusion}

A unique mesoporous crystalline structure of SAPO under structural representation as SAPO-11 support is obtained. The prepared materials are analysed and tested under the performance in the hydro-treating condition after activation with $\mathrm{H}_{2}$ atmosphere. The XRD analysis of the synthesized samples indicated that the sample prepared under ultrasonic method had high degree of crystallinity when compared to the other samples prepared with hydrothermal and ultrasonic methods combined together. The loss of crystallinity in the combined methods is mainly due to the release of high amount of heat during the oxidation process. The acid site concentrations of the prepared SAPO-11 catalysts are analysed using FTIR spectroscopy. It is observed that the ratio of medium strength Bronsted acid sites to the strong Lewis acid sites is higher for the samples synthesized by ultrasonic method. The higher Bronsted acid sites also accounted for a higher catalytic activity. The ratio of acid sites has comparatively less in the samples produced under both ultrasonic and hydrothermal conditions combined together. The SEM analysis is carried out in the produced samples to analyse the size, growth and formation of the crystals in the SAPO-11 catalyst. Also, it is observed that the crystal shape and size are relatively crystalline in the samples produced under ultrasonic method. The crystal formation and the growth of the crystal construction are better for the SAPO-11 material which prepared under ultrasonic method. Also, the results revealed that catalyst samples synthesized with n-PA as template exhibited high

Table 4. Numerical data of the GC-MS Analysis on conversion and presence of straight chained and isomerized alkanes in percentage and ratio by SAPO catalyst.

\begin{tabular}{|c|c|c|c|c|c|c|c|c|c|c|}
\hline $\begin{array}{l}\text { Oper. } \\
\text { Temp. } \\
\left({ }^{\circ} \mathrm{C}\right)\end{array}$ & Conversion & $\begin{array}{c}\text { mono } \\
\text { branched } \\
\mathrm{i}-16\end{array}$ & $\begin{array}{c}\text { di } \\
\text { branched } \\
\text { i-C16 }\end{array}$ & $\begin{array}{c}\text { iso- } \\
\text { alkanes }\end{array}$ & $\begin{array}{c}\text { n- } \\
\text { alkanes }\end{array}$ & Cracking & $\begin{array}{c}\text { Total } \\
\text { cracking }\end{array}$ & $\begin{array}{l}\text { Isomerization } \\
\text { /cracking }\end{array}$ & $\begin{array}{l}\text { iso- } \\
\text { alkanes/n- } \\
\text { alkanes }\end{array}$ & $\begin{array}{l}\text { Selectivity } \\
(\%)\end{array}$ \\
\hline 270 & 43.5 & 13.7 & 8.7 & 28.2 & 4.8 & 2.4 & 7.2 & 3.9 & 5.9 & 64.8 \\
\hline 290 & 79.1 & 17 & 9 & 48.9 & 16.6 & 5.3 & 22 & 2.2 & 2.9 & 61.9 \\
\hline 310 & 91 & 23.2 & 10.4 & 58 & 18.6 & 5.8 & 24.4 & 2.4 & 3.1 & 63.7 \\
\hline 330 & 94.3 & 18.3 & 8.7 & 61.5 & 19.2 & 6.3 & 25.4 & 2.4 & 3.2 & 65.2 \\
\hline
\end{tabular}


crystallinity and uniform distribution of acid sites over the larger surface area relative to the samples synthesized using other templates. This also attributes to the high conversion efficiency in the hydrodeoxygenation of the sunflower oil into desired large-chain hydrocarbons which are consists of branched hydrocarbons or unsaturated straight-chain hydrocarbons. Thus, the synthesized Pt/SAPO-11 catalysts can be used for various applications such as hydrocarbon processing and conversion of vegetable oil into bio-fuel with enhanced properties of fuel to use as replacement in conventional diesel.

\section{Acknowledgement}

The authors thank the SEED Grant Research Scheme (KEC/R\&D/SGRS/05/2020), KVIT Trust and FIST-DST, Department of Science and Technology (SR/FST/COLLEGE096/2017), India for the financial support.

\section{References}

[1] Palanisamy, S. Gevert, B.S. (2014). Hydroprocessing of fatty acid methyl ester containing resin acids blended with gas oil. Fuel Processing Technology, 126, 435-440, doi: 10.1016/j.fuproc.2014.05.015

[2] Le Bihan, L., Yoshimura, Y. (2002). Control of hydrodesulfurization and hydrodearomatization properties over bimetallic Pd-Pt catalysts supported on Yb-modifed USY zeolite. Fuel, 81(4), 491-494, doi: 10.1016/S00162361(01)00069-2

[3] Rajesh, M., Sau, M., Malhotra, R.K., Sharma, D.K. (2015). Hydrotreating of Gas Oil, Jatropha Oil, and Their Blends Using a Carbon Supported Cobalt-Molybdenum Catalyst. Petroleum Science and Technology, 33(19), $\begin{array}{llllllllllllll}1 & 6 & 5 & 3 & - & 1 & 6 & 5 & 9 & & & \text { d } & \text { o } & \text { i }\end{array}$ : $10.1080 / 10916466.2015 .1036291$

[4] Vonortas, A., Kubička, D., Papayannakos, N. (2014). Catalytic co-hydroprocessing of gasoilpalm oil/AVO mixtures over a NiMo/ $/-\mathrm{Al}_{2} \mathrm{O}_{3}$ catalyst. Fuel, 116, 49-55, doi: 10.1016/j.fuel.2013.07.074

[5] Sankaranarayanan, T.M., Banu, M., Pandurangan, A., Sivasanker, S. (2011). Hydroprocessing of sunflower oil-gas oil blends over sulfided Ni-Mo-Al-zeolite beta composites. Bioresource Technology, 102(22), 10717-10723, doi: 10.1016/j.biortech.2011.08.127

[6] Krár, M., Kasza, T., Kovács, S., Kalló, D., Hancsók, J. (2011). Bio gas oils with improved low temperature properties. Fuel Processing Technology, 92(5), 886-892, doi: 10.1016/j.fuproc.2010.12.007
[7] Scherzer, J., Gruia, A.J. (1996). Hydrocracking science and technology. New York: Crc Press, doi: 10.1201/9781482233889

[8] Veriansyah, B., Han, J.Y., Kim, S.K., Hong, S.A., Kim, Y.J., Lim, J.S., Shu, Y.W., Oh, S.G., Kim, J. (2011). Production of renewable diesel by hydroprocessing of soybean oil: Effect of catalysts. Fuel, 94, 578-585, doi: 10.1016/j.fuel.2011.10.057

[9] Liu, G., Tian, P., Li, J., Zhang, D., Zhou, F., Liu, Z. (2008). Synthesis, characterization and catalytic properties of SAPO-34 synthesized using diethylamine as a template. $\mathrm{Mi}$ croporous and Mesoporous Materials, 111(13 ), $143-149, \quad$ d o i : 10.1016/j.micromeso.2007.07.023

[10] Rahbari, Z.V., Khosravan, M., Kharat, A.N. (2017). Dealumination of mordenite zeolite and its catalytic performance evaluation in $\mathrm{m}$-xylene isomerization reaction. Bulletin of the Chemical Society of Ethiopia, 31(2), 281289, doi: 10.4314/bcse.v31i2.9

[11] Huang, W., Li, D., Kang, X., Shi, Y., Nie, H. (2004). Hydroisomerization of n-hexadecane on zeolite catalysts. Studies in Surface Science and Catalysis, 154C, 2353-2358, doi: 10.1016/s0167-2991(04)80497-x

[12] Taylor, R.J., Petty, R.H. (1994). Selective hydroisomerization of long chain normal paraffins. Applied Catalysis A, General, 119(1), 121-138, doi: 10.1016/0926-860X(94)85029-1

[13] Ono, Y. (2003). A survey of the mechanism in catalytic isomerization of alkanes. Catalysis Today, 81(1), 3-16, doi: 10.1016/S09205861(03)00097-X

[14] Maxwell, I.E., Stork, W.H.J. (1991). Hydrocarbon processing with zeolites. In: Studies in surface science and catalysis, Amsterdam, The Netherlands: Elsevier, pp. 571-630, doi: 10.1016/S0167-2991(08)63613-7

[15] Claude, M.C., Martens, J.A. (2000). Monomethyl-branching of long $\mathrm{n}$-alkanes in the range from decane to tetracosane on Pt/H-ZSM-22 bifunctional catalyst. Journal of Catalysis, 190(1), 39-48, doi: 10.1006/jcat.1999.2714

[16] Rabaev, M., Landau, M.V., Vidruk-Nehemya, R., Goldbourt, A., Herskowitz, M. (2015). Improvement of hydrothermal stability of Pt/SAPO-11 catalyst in hydrodeoxygenationisomerization-aromatization of vegetable oil. Journal of Catalysis, 332, 164-176, doi: 10.1016/j.jcat.2015.10.005.

[17] Campelo, J.M., Lafont, F., Marinas, J.M. (1998). Hydroconversion of n-dodecane over Pt/SAPO-11 catalyst. Applied Catalysis A: General, 170(1), 139-144, doi: 10.1016/S0926860X(98)00036-2 
[18] Palanisamy, S., Gevert, B.S. (2018). Hydrodeoxygenation of fatty acid methyl ester in gas oil blend-NiMoS/alumina catalyst. Green Processing and Synthesis, 7(3), 260-267, doi: 10.1515/gps-2016-0117

[19] Askari, S., Halladj, R. (2013). Effects of ultrasound-related variables on sonochemically synthesized SAPO-34 nanoparticles. Journal of Solid State Chemistry, 201, 85-92, doi: 10.1016/j.jssc.2013.02.026

[20] Palanisamy, S., Gevert, B.S. (2016). Study of non-catalytic thermal decomposition of triglyceride at hydroprocessing condition. Applied Thermal Engineering, 107, 301-310, doi: 10.1016/j.applthermaleng.2016.06.167

[21] Askari, S., Halladj, R., Nazari, M. (2013). Statistical analysis of sonochemical synthesis of SAPO-34 nanocrystals using Taguchi experimental design. Materials Research Bulletin, 48 ( 5 ), $\quad 1851-1856, \quad$ d o i : 10.1016/j.materresbull.2013.01.021

[22] Blasco, T., Chica, A., Corma, A., Murphy, W.J., Agúndez-Rodríguez, J., Pérez-Pariente, J. (2006). Changing the Si distribution in SAPO-11 by synthesis with surfactants improves the hydroisomerization/dewaxing properties. Journal of Catalysis, 242(1), 153-161, doi: 10.1016/j.jcat.2006.05.027

[23] Lok, B.M., Messina, C.A., Patton, R.L., Gajek, R.T., Cannan, T.R., Flanigen, E.M. (1984). Silicoaluminophosphate molecular sieves: another new class of microporous crystalline inorganic solids. Journal of the American Chemical Society, 106(20), 6092-6093, doi: 10.1021/ja00332a063

[24] Zhang, S., Chen, S.L., Dong, P., Yuan, G., Xu, K. (2007). Characterization and hydroisomerization performance of SAPO-11 molecular sieves synthesized in different media. Applied Catalysis A: General, 332(1), 46-55, doi: 10.1016/j.apcata.2007.07.047

[25] Liu, P., Ren, J., Sun, Y. (2008). Influence of template on Si distribution of SAPO-11 and their performance for n-paraffin isomerization. Microporous and Mesoporous Materials, $114(1-3), \quad 365-372, \quad$ d o i : 10.1016/j.micromeso.2008.01.022

[26] Meriaudeau, P., Tuan, V.A., Lefebvre, F., Nghiem, V.T., Naccache, C. (1998). Isomorphous substitution of silicon in the AlPO4 framework with AEL structure: N-octane hydroconversion. Microporous and Mesoporous Materials, 22(1-3), 435-449, doi: 10.1016/S1387-1811(98)00095-X

[27] Yang, L., Aizhen, Y., Qinhua, X. (1990). Acidity, diffusion and catalytic properties of the silicoaluminophosphate SAPO-11. Applied Catalysis, 67(1), 169-177, doi: 10.1016/S01669834(00)84440-1
[28] Ping, L., Jie, R.E.N., Yuhan, S. (2008). Acidity and isomerization activity of SAPO-11 synthesized by an improved hydrothermal method. Chinese Journal of Catalysis, 29(4), 379384, doi: 10.1016/S1872-2067(08)60034-0

[29] Doan, T., Nguyen, K., Dam, P., Vuong, T.H., Le, M.T., Thanh, H.P. (2019). Synthesis of SAPO-34 Using Different Combinations of Organic Structure-Directing Agents. Journal of Chemistry, 2019, 6197527, doi: $10.1155 / 2019 / 6197527$

[30] Marchese, L., Frache, A., Gianotti, E., Martra, G., Causa, M., Coluccia, S. (1999). ALPO34 and SAPO-34 synthesized by using morpholine as templating agent. FTIR and FTRaman studies of the host-guest and guestguest interactions within the zeolitic framework. Microporous and Mesoporous Materials, 30(1), 145-153, doi: 10.1016/S13871811(99)00023-2.

[31] Meriaudeau, P., Tuan, V.A., Nghiem, V.T., Lai, S.Y., Hung, L.N., Naccache, C. (1997). SAPO-11, SAPO-31, and SAPO-41 molecular sieves: Synthesis, characterization, and catalytic properties in n-octane hydroisomerization. Journal of Catalysis, 169(1), 55-66, doi: 10.1006/jcat.1997.1647

[32] Parlitz, B., Schreier, E., Zubowa, H.L., Eckelt, R., Lieske, E., Lischke, G., Fricke, R. (1995). Isomerization of n-heptane over Pdloaded silico-alumino-phosphate molecular sieves. Journal of Catalysis, 155(1), 1-11, doi: 10.1006/jcat.1995.1182

[33] Verma, D., Rana, B.S., Kumar, R., Sibi, M.G., Sinha, A.K. (2015). Diesel and aviation kerosene with desired aromatics from hydroprocessing of jatropha oil over hydrogenation catalysts supported on hierarchical mesoporous SAPO-11. Applied Catalysis A: General, $490(1), \quad 108-116, \quad \mathrm{~d}$ o i : 10.1016/j.apcata.2014.11.007

[34] Kumar, R., Rana, B.S., Tiwari, R., Verma, D., Kumar, R., Joshi, R.K., Garg, M.O., Sinha, A.K. (2010). Hydroprocessing of jatropha oil and its mixtures with gas oil. Green Chemistry, 12(12), 2232-2239, doi: $10.1039 / \mathrm{cogc00204f}$

[35] Rathore, V., Newalkar, B.L., Badoni, R.P. (2016). Processing of vegetable oil for biofuel production through conventional and nonconventional routes. Energy for Sustainable Development, $\quad 31, \quad 24-49, \quad$ doi: 10.1016/j.esd.2015.11.003.

[36] Filhoda Rocha, G.N., Brodzki, D., DjégaMariadassou, G. (1993). Formation of alkanes, alkylcycloalkanes and alkylbenzenes during the catalytic hydrocracking of vegetable oils. Fuel, 72(4), 543-549, doi: 10.1016/0016-2361(93)90114-H 
[37] Chen, N., Gong, S., Qian, E.W. (2015). Effect of reduction temperature of NiMoO3-x/SAPO11 on its catalytic activity in hydrodeoxygenation of methyl laurate. Applied Catalysis B: Environmental, 174-175, 253-263, 10.1016/j.apcatb.2015.03.011

[38] Chen, N., Ren, Y., Qian, E.W. (2016). Elucidation of the active phase in PtSn/SAPO-11 for hydrodeoxygenation of methyl palmitate. Journal of Catalysis, 334, 79-88, doi: 10.1016/j.jcat.2015.11.001
[39] Pattanaik, B.P., Misra, R.D. (2017). Effect of reaction pathway and operating parameters on the deoxygenation of vegetable oils to produce diesel range hydrocarbon fuels: A review. Renewable and Sustainable Energy Revi ews, $73, \quad 545-557, \quad \mathrm{~d}$ o i : 10.1016/j.rser.2017.01.018

[40] Palanisamy, S., Kandasamy, K. (2020). Direct Hydrogenation and Hydrotreating of Neat Vegetal Oil into Renewable Diesel Using Alumina Binder with Zeolite. Rev. Chim., 71(9), 98-112, doi: 10.37358/RC.20.9.8321 